\title{
INJURE AND LAW LIABILITY
}

Viktor I. Tsyganov

N.I. Lobachevsky State University of Nizhny Novgorod, Nizhny Novgorod, Russian Federation

\author{
Aleksey A. Demin \\ N.I. Lobachevsky State University of Nizhny Novgorod, Nizhny Novgorod, Russian Federation
}

Introduction: the legal regulation of the relations on compensation of harm has always been a subject of interest to the jurists. The vast majority of researchers of the relations associated with damages associated with their category of civil liability. However, in the legal literature is justified liability the legal nature of considered relations, in this connection, the authors set the purpose of the research available positions by the author about the legal nature of the relationship of the damage caused. Methods: the methodological basis of this study constitute a set of scientific methods, among which the main place is occupied by the historical method, systemic analysis and comparative-legal. Results: grounded in the work of the author's position is based on the law and the opinion of the competent scientific community on the issues of obligations and legal relations connected with compensation of the harm caused. On the basis of the analysis examines the conditions of civil liability, the analysis of the current civil law, the basic existing in theory of law the position of the authors regarding responsibility, social responsibility, and legal liability as a form of social responsibility. Conclusion: in the study it is proposed to change the existing in modern civic science approach to the legal nature of legal relations connected with compensation of the harm caused. The authors indicated that in modern civil-legal regulation it is necessary to revise the view of compensation of the harm caused as to civil liability in favor of its contractual nature. It is noted that this approach is due to legal stipulations to this type of legal relations that requires a deep scientific study.

Key words: injure, damage, property damage, trespass, liability, tort, extra-contractual liability.

УДК 347

ББК 67.0

\section{ПРИЧИНЕНИЕ ВРЕДА И ЮРИДИЧЕСКАЯ ОТВЕТСТВЕННОСТЬ}

\author{
Виктор Иванович Цыганов \\ Нижегородский государственный университет им. Н.И. Лобачевского, \\ г. Нижний Новгород, Российская Федерация
}

\section{Алексей Александрович Демин}

\author{
Нижегородский государственный университет им. Н.И. Лобачевского, \\ г. Нижний Новгород, Российская Федерация
}

Введение: нормативно-правовое регулирование отношений по возмещению причиненного вреда традиционно является предметом интереса цивилистов. Абсолютное большинство исследователей связанных с возмещением причиненного ущерба отношений соотносят их с категорией гражданско-правовой ответственности. Вместе с тем в юридической литературе обосновывается обязательственная правовая природа рассматриваемых отношений, в связи с чем авторами в работе поставлена цель исследования имеющихся позиций относительно правовой природы отношений возмещения причиненного вреда. Методы: методологическую основу данного исследования составляет совокупность методов научного познания, среди которых основное место занимают исторический и сравнительно-правовой методы, методы системности и анализа. Результаты: обоснованная в работе авторская позиция опирается на законодательство и мнения компетентной научной среды по вопросам обязательств, а также правовых отношений, связанных с возмещени- 
ем причиненного вреда. На основании анализа изучаются условия гражданско-правовой ответственности, проведен анализ действующего гражданского законодательства, изучены основные существующие в теории права позиции авторов относительно ответственности (социальной, а также юридической ответственности как вида социальной ответственности). Выводы: в результате проведенного исследования предлагается изменить существующий в современной цивилистической науке подход к правовой природе правоотношений, связанных с возмещением причиненного вреда. Авторами указывается, что в условиях современного гражданско-правового регулирования необходимо пересмотреть взгляд на возмещение причиненного вреда как на гражданско-правовую ответственность в пользу ее обязательственной природы. При этом отмечается, что такой подход обусловлен законодательными установлениями к данному виду правоотношений, что требует глубокой научной проработки.

Ключевые слова: причинение вреда, ущерб, возмещение вреда, имущественный вред, правонарушение, ответственность, деликт, внедоговорная ответственность.

\section{Введение}

Проблеме юридической ответственности посвящено немало работ, где ответственность понимается как мера государственного принуждения с применением к правонарушителю предусмотренных нормой санкций, выражающихся в форме лишений, неблагоприятных последствий личного, организационного или имущественного характера [18, c. 599]. Также подчеркивается, что юридическая ответственность неоднородна и подразделяется по отраслевой принадлежности с присущими каждой отрасли особенностями. Такой подход закрепился в теории права.

\section{Основные подходы к определению гражданско-правовой ответственности и ее особенностей}

В гражданском праве наряду с договорной ответственностью (ответственностью за нарушение обязательств) изучают деликтную ответственность. Причинение вреда - это нарушение общего запрета, а значит - правонарушение - и поэтому вести речь об ответственности вроде бы логично. Вместе с тем, характеризуя гражданско-правовую ответственность, О.С. Иоффе называет в качестве ее отраслевых особенностей: 1) возможность добровольного совершения действий, направленных на устранение последствий совершенного правонарушения, то есть без применения государственного аппарата; 2) наличие отрицательных последствий для правонарушителя, которые направлены на восстановление прежнего положения потерпевшего; 3) целью применения мер ответственности является не общественное осуждение поведения правона- рушителя, а лишь его стимулирование к определенному поведению [7, с. 196-207]. Особенности гражданско-правовой ответственности выделяет и О.А. Красавчиков, подчеркивая ее a) нормативную обоснованность; б) специфическую социальную направленность, выражающуюся в восстановительной и предупредительной функциях [8, с. 260]. Н.В. Витрук отмечает, что гражданско-правовая ответственность в своем содержании прежде всего и главным образом состоит в восстановлении нарушенного права (правового состояния), в заглаживании нанесенного в результате неправомерного действия вреда, возмещении ущерба в натуре либо в виде компенсации [3, с. 259]. По мнению других ученых, гражданско-правовая ответственность как разновидность юридической ответственности представляет собой реализацию конкретной меры ответственности (определенной санкции), предусмотренной законом или договором. Реализация этих санкций, мер ответственности обеспечивается государственным принуждением [14, с. 79-101].

\section{Основания привлечения правонарушителя к ответственности}

Как основание для привлечения правонарушителя к юридической ответственности в теории гражданского права признают факт правонарушения (неправомерное действие). К условиям наступления гражданско-правовой ответственности относят: противоправность ${ }^{1}$, вред $^{2}$, наличие причинно-следственной связи ${ }^{3}$, вину ${ }^{4}$. Утверждение, что лицо, причинившее имущественный вред потерпевшему, при возмещении вреда подвергается гражданскоправовой ответственности, является устояв- 
шимся в цивилистике и не подвергается сколько-нибудь серьезному сомнению ни в теоретических разработках ученых, ни в судебной практике. Так, высшие судебные инстанции указывают, что по делам о возмещении вреда суд должен установить факт причинения вреда, вину причинителя вреда и причинноследственную связь между незаконными действиями (бездействием) причинителя вреда и причиненным вредом [12; 13]. При этом на страницах юридической литературы предлагаются различные подходы к учету вины, к причинно-следственной связи, к основаниям и условиям возникновения ответственности и установления обязательств вследствие причинения вреда.

Также нет единообразия в понимании правовой природы рассматриваемых категорий. Например, учеными еще советского периода высказывалась мысль о том, что обязательства из причинения вреда не следует считать ответственностью. Так, О.А. Красавчиков полагает, что обязанность возместить вред, причиненный невиновным действием, не может быть ответственностью, а представляет собой форму восстановления имущественного положения потерпевшего [8, с. 404]. Также О.Э. Лейст указывает, что, например, ответственность без учета вины на самом деле не ответственность, а особый, отличный от ответственности способ восстановления имущественных прав лица, пострадавшего от правонарушения [9, с. 131-133]. Схожее мнение по данному вопросу высказано и другими учеными, например, Г.К. Матвеевым, который в случаях безвиновного поведения предлагает «говорить не об ответственности, а об обязанности возместить вред или уплатить штраф» [11, с. 28-36]. По мнению А.А. Тебряева, «там, где нет вины в связи с установленными законом юридическими фактами, у одного лица возникает по отношению к другому не ответственность, а обязанность возместить убытки, то есть мера защиты, и там же, где налицо вина, появляется ответственность» $[17$, с. 28$]$. Весьма оригинален в вопросе разграничения ответственности и обязательств вследствие причинения вреда Ю.К. Толстой, который предлагал различать условия возникновения ответственности за причинение вреда и условия возникновения обязательств из причинения вреда, не относя их к мерам ответственности: «В тех случаях, когда обязанность возмещения вреда является мерой ответственности, в ее основе лежит состав правонарушения (полный или усеченный). < ..> Если же обязанность возмещения вреда не относится к мерам ответственности, то в основе возникновения указанной обязанности лежат иные условия, которые состава правонарушения не образуют». И в любом случае, утверждает автор, «к мерам гражданско-правовой ответственности нельзя отнести обязанность возмещения вреда, причиненного правомерным действием, независимо от того, возлагается ли эта обязанность на причинителя вреда или на какое-то другое лицо» [20, с. 1119]. В приведенных примерах ученые нашли возможным признать обязанность по возмещению вреда способом (формой) восстановления имущественных прав лица, пострадавшего от правонарушения, а не мерой гражданско-правовой ответственности. Как известно, данная обязанность возникает и исполняется в обязательстве вследствие причинения вреда. Нет ли противоречия в позиции, что при невиновном причинении вреда деликтное обязательство не является мерой ответственности, а при виновном является? И не должна ли оставаться неизменной сущностная природа одной и той же гражданско-правовой категории?

Более того, на это нас ориентирует и законодатель, который отношения по возмещению вреда называет в качестве особого вида обязательственных правоотношений. Та же мысль явно прослеживается в «Концепции развития гражданского законодательства Российской Федерации» ${ }^{5}$, а впоследствии и во внесенных изменениях в гражданское законодательство (ст. 307.1 ГК РФ), которые ориентируют на применение общих положений об обязательствах во внедоговорных отношениях, в частности, в отношениях, связанных с возмещением причиненного вреда. Это не может не свидетельствовать о необходимости пересмотра отдельных постулатов в отношениях по возмещению имущественного вреда.

Во-первых, следует поддержать О.А. Красавчикова в том, что обязанность возместить вред, причиненный невиновным действием, 
не может быть ответственностью и устанавливается с целью восстановления имущественного положения потерпевшего. Надо также признать, что юридическая ответственность тоже может преследовать эти цели, но через применение иных мер, а не посредством обязанности по возмещению вреда. Иной подход вынуждает авторов делать выводы, что функции ответственности кардинально различаются: «основная функция гражданско-правовой ответственности - компенсационная (восстановительная). Этим она кардинально отличается от других видов ответственности, в частности, от уголовной» $[1$, c. 14-20]. Хотя вряд ли правильно считать, что одна и та же юридическая категория, обладая одним и тем же назначением, может функционировать по-разному и преследовать разные цели.

Во-вторых, заметим изменение подхода законодателя к категории противоправности. Ученые считают, что если рассматривать возмещение вреда в качестве гражданско-правовой ответственности, то необходимым условием для возмещения является противоправность. Однако ст. 16.1 ГК РФ предусматривает возможность компенсации ущерба, причиненного личности или имуществу гражданина правомерными действиями государственных органов, органов местного самоуправления или должностных лиц этих органов, а также иных лиц, которым государством делегированы властные полномочия. Более того, «если действие нарушает право и причиняет вред, то никакой “дополнительной” противоправности для возникновения правоотношения не требуется, независимо от того, понимаем ли мы под противоправностью нарушение объективного или одновременно субъективного права» [5, с. 891]. Тем самым, такой признак как противоправность не является непоколебимым условием установления обязательства по возмещению ущерба. Причем вызывает сомнение и то, что обязанность восстановить причиненный правомерными действиями ущерб вообще можно назвать ответственностью, ибо ответственность должна наступать за противоправные действия, а не за действия, осуществляемые в рамках и на основании закона.

Другим условием наступления ответственности считается наличие вины, а в не- которых случаях предусматривается ответственность и при отсутствии вины. В юридической литературе такой вид ответственности получил наибольшую поддержку и именуется концепцией «вины с исключением» $[8$, с. 258]. При этом категория вины является наиболее сложной как для разработки теоретического материала, так и для правоприменителя, поскольку вина является субъективным (внутренним) отражением содеянного.

По этому поводу отмечается, что «К сожалению, до настоящего времени в современной юридической литературе практически отсутствует теоретический анализ вины как условия гражданско-правовой ответственности, а доктрина гражданского права по инерции продолжает в основном оставаться на прежних позициях, смысл которых заключается в поиске все новых объяснений необходимости применения в цивилистике чуждых ей уголовно-правовых взглядов на вину как на один из элементов состава правонарушения, представляющих собой некое гипотетическое психическое отношение правонарушителя к своим действиям и их последствиям [2, с. 848]. В свою очередь В.П. Грибанов отмечает, что определить уголовно-правовую ответственность намного легче, чем гражданско-правовую. Это связано с большей сферой регулирования общественных отношений гражданским правом, чем уголовным [6, с. 299].

При этом не следует забывать, что отношения гражданско-правовые отличаются от уголовно-правовых частным характером, где на первом месте должны выступать юридическое равенство, имущественная обособленность, организационная самостоятельность субъектов и их частный интерес. А если имеется частный интерес, то должна быть и специфика защиты такого интереса. Иначе, «сводить же все меры гражданско-правового воздействия на правонарушителя лишь к мерам ответственности - это в лучшем случае сужать арсенал гражданско-правовых средств воздействия на общественные отношения» [8, c. 259]. Такой же позиции придерживается и В.П. Грибанов, по мнению которого гражданско-правовая ответственность - это не единственное, а одно из многих «средств защиты гражданских прав и воздействия на наруши- 
телей обязанностей» [6, с. 299]. Тем самым, следует поддержать точку зрения, согласно которой категория вины в настоящее время является недостаточно разработанной в целях ее применения для привлечения к гражданско-правовой ответственности, в частности, в отношениях, связанных с возмещением причиненного вреда.

Представляется, что в связи с этим необходимо пересмотреть вопрос правовой природы отношений по возмещению причиненного вреда, подчеркнув их обязательственную природу, обладающую сущностными особенностями по сравнению с отношениями ответственности. В этом плане показателен пример, приведенный А.О. Гордоном, который пишет: «Человек поскользнулся, упал и разбил мою ценную вещь. Положим даже, что он упал от того, что с ним случилось головокружение... Его ни в чем упрекнуть нельзя. Это несчастье. Но мне от этого не легче. Я тут уже решительно ни в чем не повинен» [4, с. 38]. Другими словами, потерпевший вообще не виноват в том, что ему причинили ущерб, и вопрос виновности или невиновности причинителя вреда не должен влиять на его имущественное состояние.

Еще один довод в пользу того, что обязательства по возмещению вреда не следует относить к мерам ответственности, находим в работе А.Б. Бабаева: «выделяются три следующих признака юридической ответственности: 1) отрицательная оценка действий лица, на которого возлагается ответственность (осуждение); 2) государственное принуждение или возможность его применения; 3) наличие дополнительных обременений или новых обязанностей для правонарушителя» [5, с. 868]. Далее автор отмечает, что «легко заметить, что при таких "особенностях" гражданско-правовая ответственность никак "не вписывается" в перечисленные выше, якобы родовые признаки понятия юридической ответственности вообще. Отсюда может следовать лишь один из двух равновозможных выводов: либо неверно определение родового понятия юридической ответственности в целом, либо то явление, которое обозначается термином "гражданско-правовая ответственность", не является ответственностью» $[5$, с. 868].
И действительно, взять, к примеру, такой признак, как наличие дополнительных обременений (неблагоприятных дополнительных последствий) или возложение новых обязанностей на правонарушителя. Представляется, что в отношениях по возмещению причиненного ущерба не может считаться неблагоприятным последствием обязанность восстановления имущественного положения потерпевшего. Такая обязанность - это благо для потерпевшего, а с позиции социальной справедливости и для причинителя вреда тоже. Таким образом, когда признак неблагоприятных последствий отсутствует, применяемые к должнику меры не должны считаться ответственностью.

При этом, утверждение о том, что ответственность - это всегда дополнительные возложения на правонарушителя, контрастирует с тем, что целью гражданско-правовой ответственности является восстановление имущественного положения либо компенсация понесенных потерь (восстановительная функция) $[15$, с. 50$]$. Целью возложения ответственности всегда является воздействие на личность или имущество правонарушителя, результатом которого являются определенные лишения. При этом восстановление имущественного положения потерпевшего может происходить, а может и не происходить: для юридической ответственности это не главный, а дополнительный эффект. В то время как для деликтного обязательства восстановление имущественного положения потерпевшего - это главная и единственная цель. Еще одно соображение: если ответственность должна носить стимулирующий характер, то в обязательствах по возмещению вреда вряд ли можно говорить о стимулирующей функции возмещения вреда. Ведь даже если субъект гражданского права знает о том, что он будет возмещать причиненный ущерб, например, вследствие ДТП, то, как правило, такой ущерб причиняется ненамеренными действиями и без оглядки на существование «ответственности». Если же ущерб причиняется намеренно, такие действия должны быть квалифицированы в качестве уголовного правонарушения, и тогда наряду с возмещением вреда наступает уголовная ответственность (штраф, лишение свободы, принудительные работы и пр.). 
По утверждению Р.Л. Хачатурова и Д.А. Липинского, социальная ответственность едина, но имеет две формы реализации: добровольную и принудительную. При добровольной субъект следует предписаниям социальных норм в своем правомерном поведении, а принудительная выражается «в обязанности нарушителя социальных норм подвергнуться определенным мерам общественного и (или) государственного принуждения, понести неблагоприятные последствия и реализации этих последствий» [22, с. 22]. Однако при соблюдении предписаний, когда ничего еще не нарушено, вопрос об ответственности не может ставиться в принципе, a, например, обязательственные отношения по возмещению вреда могут возникнуть на основании соглашения между причинителем вреда и потерпевшим, то есть добровольным принятием на себя обязанности со стороны причинителя вреда.

\section{Выводы}

Таким образом, отношения по возмещению вреда имеют достаточно спорную правовую природу, что традиционно отмечается учеными. И подход современного законодателя свидетельствует о необходимости пересмотра подходов к пониманию обязательственных правоотношений по возмещению причиненного вреда. Указанные отношения возникают между независимыми и равными участниками гражданского оборота, где инициатива возникновения, изменения и прекращения гражданских прав и обязанностей, в том числе и в процессе защиты нарушенных прав, принадлежит частным лицам. Поэтому заимствованные у других отраслей права категории, в частности юридической ответственности, должны быть пересмотрены с учетом частно-правового интереса автономных участников гражданского оборота.

\section{ПРИМЕЧАНИЯ}

1 Под противоправностью понимается нарушение норм объективного права [16].

${ }^{2}$ Вред рассматривается как умаление или уничтожение блага $[10$, с. 7$]$.
${ }^{3}$ Причинно-следственная связь чаще всего рассматривается как связь между совершенными действиями и наступившими последствиями.

${ }^{4}$ Вину принято рассматривать в качестве субъективной категории, отражающей внутреннее отношение лица, совершившего правонарушение, к содеянному и наступившим последствиям [21, с. 60].

${ }^{5}$ Одобрена решением Совета при Президенте РФ по кодификации и совершенствованию гражданского законодательства от 7 октября 2009 года.

\section{СПИСОК ЛИТЕРАТУРЫ}

1. Агибалова, Е. Н. Состав гражданского правонарушения как основание деликтной ответственности / Е. Н. Агибалова // Научный вестник Волгоградской академии государственной службы. - Волгоград, 2010. - № 7. - С. 14-20.

2. Брагинский, М. И. Договорное право. Общие положения / М. И. Брагинский, В. В. Витрянский. - 3-е изд. - М. : Статут, 2001. -848 c.

3. Витрук, Н. В. Общая теория юридической ответственности / Н. В. Витрук. - М. : Норма, 2009. $304 \mathrm{c}$.

4. Гордон, А. О. Принцип ответственности железных дорог за ущерб, причиненный при эксплуатации / А. О. Гордон. - СПб. : Тип. Правительствующего Сената, 1887. $-115 \mathrm{c}$.

5. Гражданское право: актуальные проблемы теории и практики / под ред. В. А. Белова. - М. : Юрайт, 2009. - 1009 с.

6. Грибанов, В. П. Осуществление и защита гражданских прав / В. П. Грибанов. - 2-е изд. - М. : Статут, 2001. $-411 \mathrm{c}$.

7. Иоффе, О. С. Избранные труды: Правоотношение по советскому гражданскому праву. Ответственность по советскому гражданскому праву / О. С. Иоффе. - СПб. : Юридический центр Пресс, 2003. - C. 196-207.

8. Красавчиков, О. А. Категории науки гражданского права. Избранные труды / О. А. Красавчиков. - М. : Статут, 2005. - 492 с.

9. Лейст, О. Э. Санкции и ответственность по советскому праву / О. Э. Лейст. - М. : Изд-во Моск. ун-та, 1981. - С. 131-133.

10. Малеин, Н. С. Возмещение вреда, причиненного личности / Н. С. Малеин. - М. : Юрид. лит, 1965. $-230 \mathrm{c}$.

11. Матвеев, Г. К Основания юридической ответственности / Г. К. Матвеев // Советское государство и право. - 1971. - № 10. - С. 28-36.

12. Определение Верховного суда РФ от 24 окт. 2017 г. № 49-КГ17-21. - Доступ из справ.-правовой системы «КонсультантПлюс» (дата обращения: 02.01.2018). 
13. Определение Конституционного суда РФ «Об отказе в принятии к рассмотрению жалобы гражданина М.Ж. Восканяна на нарушение его конституционных прав статьями 15, 1069 и 1070 Гражданского кодекса Российской Федерации» от 05 апр. 2016 г. № 701-О. - Доступ из справ.-правовой системы «КонсультантПлюс» (дата обращения 02.01.2018).

14. Попондопуло, В. Ф. Ответственность за нарушение обязательств: общая характеристика и проблемы. Вопросы правоприменительной практики / В. Ф. Попондопуло // Ленинградский юридический журнал. - 2010. - № 1. - С. 79-101.

15. Смирнов, В. Т. Общее учение о деликтных обязательствах в советском гражданском праве: учеб. пособие / В. Т. Смирнов, А. А. Собчак. - Л. : ЛГУ, 1983. - $152 \mathrm{c}$.

16. Тархов, В. А. Ответственность по советскому гражданскому праву / В. А. Тархов. - Саратов : Изд-во Саратовского ун-та, 1973. - С. 60-61.

17. Тебряев, А. А. Вина причинителя вреда в деликтных обязательствах / А. В. Тебряев // Юрист. 2002. - № 3. - С. 28.

18. Теория государства и права: курс лекций / под ред. Н. И. Матузова, А. В. Малько. - 2-е изд. М. : Юристь, 2001. -776 с.

19. Теория государства и права: учебник для студентов вузов / под ред. проф. В. М. Корельского, проф. В. Д. Перевалова. - 2-е изд. - М. : Норма, 2002. $-616 \mathrm{c}$.

20. Толстой, Ю. К. Обязательства, возникающие вследствие причинения вреда // Гражданское право / под ред. А. П. Сергеева, Ю. К. Толстого. - 4-е изд. М. : ТК «Велби» : Проспект, 2005. -С. 11-19.

21. Флейшиц, Е. А. Обязательства из причинения вреда и из неосновательного обогащения / Е. А. Флейшиц. - М. : Госюриздат, 1951. - 239 с.

22. Хачатуров, Р. Л. Общая теория юридической ответственности / Р. Л. Хачатуров, Д. А. Липинский. - СПб. : Юридический центр Пресс, 2007. $950 \mathrm{c}$

\section{REFERENCES}

1. Agibalova E.N. Sostav grazhdanskogo pravonarusheniya kak osnovanie deliktnoy otvetstvennosti [The Elements of a Civil Violation as a Basis of Tort Liability]. Nalogi, 2010, no. 7, pp. 14-20.

2. Braginskiy M.I., Vitryanskiy V.V. Dogovornoe pravo. Obshchie polozheniya [The Contractual Law. General Provisions]. Moscow, Statut Publ., 2001. 848 p.

3. Vitruk N.V. Obshchaya teoriya yuridicheskoy otvetstvennosti [The General Theory of Legal Liability]. Moscow NORMA Publ., 2009. 304 p.

4. Gordon A.O. Printsip otvetstvennosti zheleznykh dorog za ushcherb, prichinennyy pri ekspluatatsii [The Principle of Railways Responsibility for Damage Caused During Operation]. Saint Petersburg, Tip. Pravitelstvuyushchego Senata, $1887.115 \mathrm{p}$.

5. Belov V.A., ed. Grazhdanskoe pravo: aktualnye problemy teorii i praktiki [The Civil Law: Relevant Problems of Theory and Practice]. Moscow, Yurayt Publ., 2009. 1009 p.

6. Gribanov V.P. Osushchestvlenie $i$ zashchita grazhdanskikh prav [Execution and Protection of Civil Rights]. Moscow, Statut Publ., 2001. 411 p.

7. Ioffe O.S. Izbrannye trudy: Pravootnoshenie po sovetskomu grazhdanskomu pravu. Otvetstvennost po sovetskomu grazhdanskomu pravu [Selected Works: Legal Relationship under the Soviet Civil Law. Responsibility under the Soviet Civil Law]. Saint Petersburg, Yuridicheskiy tsentr Press, 2003, pp. 196-207.

8. Krasavchikov O.A. Kategorii nauki grazhdanskogo prava. Izbrannye trudy [The Categories of the Science of Civil Law. Selected Works]. Moscow, Statut Publ., 2005. 492 p.

9. Leyst O.E. Sanktsii $i$ otvetstvennost po sovetskomu pravu [Sanctions and Responsibility under the Soviet Law]. Moscow, Izd-vo Mosk. un-ta, 1981, pp. 131-133.

10. Malein N.S. Vozmeshchenie vreda, prichinennogo lichnosti [Compensation of Harm Caused to a Person]. Moscow, Yurid. lit. Publ., 1965. $230 \mathrm{p}$.

11. Matveev G.K. Osnovaniya yuridicheskoy otvetstvennosti [Grounds for Legal Liability]. Sovetskoe gosudarstvo i pravo, 1971, no. 10, pp. 28-36.

12. Opredelenie Verkhovnogo suda RF ot 24 okt. 2017 g. N49-KG17-21 [Decision of the Supreme Court of the Russian Federation of October 24, 2017 no. 49KG17-21]. URL: http://www.consultant.ru/cons/cgi/ online.cgi?req $=$ doc; base $=A R B ; n=518942 \# 0$ (accessed January 2, 2018).

13. Opredelenie Konstitutsionnogo suda RF «Ob otkaze $v$ prinyatii $k$ rassmotreniyu zhaloby grazhdanina M.Zh. Voskanyana na narushenie ego konstitutsionnykh prav statyami 15, 1069 i 1070 Grazhdanskogo kodeksa Rossiyskoy Federatsii» ot 05 apr. 2016 g. N 701-O [Decision of the Constitutional Court of the Russian Federation "On Rejection to Consider the Claim of M.Zh. Voskanyan on the Violation of His Constitutional Rights under Articles 15, 1069, 1070 of the Civil Code of the Russian Federation" of April 5, 2016 no. 701-O]. URL: http://www. consultant.ru/cons/cgi/online.cgi?req=doc; base $=$ $A R B ; n=459266 \# 0$ (accessed January 2, 2018).

14. Popondopulo V.F. Otvetstvennost za narushenie obyazatelstv: obshchaya kharakteristika i problemy. Voprosy pravoprimenitelnoy praktiki [Responsibility for Violation of Obligations: General Characteristica and Problems. The Issues of Law 
Enforcement Practice]. Leningradskiy yuridicheskiy zhurnal, 2010, no. 1, pp. 79-101.

15. Smirnov V.T., Sobchak A.A. Obshchee uchenie o deliktnykh obyazatelstvakh $v$ sovetskom grazhdanskom prave [The General Doctrine of Tort Obligations in the Soviet Civil Law]. Leningrad, LGU Publ., 1983. 152 p.

16. Tarkhov V.A. Otvetstvennost po sovetskomu grazhdanskomu pravu [The Responsibility for Soviet Civil Law]. Saratov, Izd-vo Saratovskogo un-ta, 1973, pp. 60-61.

17. Tebryaev A.A. Vina prichinitelya vreda $\mathrm{V}$ deliktnykh obyazatelstvakh [The Blame of the HarmBearer in Tort Obligations]. Yurist, 2002, no. 3, p. 28.

18. Matuzov N.I., Malko A.V., eds. Teoriya gosudarstva i prava: kurs lektsiy [The Theory of State and Law]. Moscow, Yurist Publ., 2001. 776 p.
19. Korelskiy V.M., Perevalov V.D., eds. Teoriya gosudarstva i prava: uchebnik dlya studentov vuzov [The Theory of State and Law: University Textbook]. Moscow, NORMA Publ., 2002. 616 p.

20. Tolstoy Yu.K. Obyazatelstva, voznikayushchie vsledstvie prichineniya vreda [Obligations arising from the infliction of harm]. Sergeev A.P., Tolstoy Yu.K., eds. Grazhdanskoe pravo: uchebnik [The Civil Law: Textbook]. Moscow, Velbi Publ.; Prospekt Publ., 2005, pp. 11-19.

21. Fleyshits E.A. Obyazatelstva iz prichineniya vreda i iz neosnovatelnogo obogashcheniya [Obligations Raising Due to Causing Harm and Due to Unjust Enrichment]. Moscow, Gosyurizdat Publ., 1951.239p.

22. Khachaturov R.L., Lipinskiy D.A. Obshchaya teoriya yuridicheskoy otvetstvennosti [The General Theory of Legal Responsibility]. Saint Petersburg, Yuridicheskiy tsentr Press, 2007. 950 p.

\section{Information about the Authors}

Viktor I. Tsyganov, Candidate of Juridical Sciences, Associate Professor, Dean of the Faculty of Law, N.I. Lobachevsky State University of Nizhny Novgorod, Prosp. Gagarina, 23, 603950 Nizhny Novgorod, Russian Federation, ziganovw@yandex.ru.

Aleksey A. Demin, Candidate of Juridical Sciences, Associate Professor, Department of Civil Law and Procedure, Faculty of Law, N.I. Lobachevsky State University of Nizhny Novgorod, Prosp. Gagarina, 23,603950 Nizhny Novgorod, Russian Federation, bullpit@rambler.ru.

\section{Информация об авторах}

Виктор Иванович Цыганов, кандидат юридических наук, доцент, декан юридического факультета, Нижегородский государственный университет им. Н.И. Лобачевского, просп. Гагарина, 23, 603950 г. Нижний Новгород, Российская Федерация, ziganovw@yandex.ru.

Алексей Александрович Демин, кандидат юридических наук, доцент кафедры гражданского права и процесса юридического факультета, Нижегородский государственный университет им. Н.И. Лобачевского, просп. Гагарина, 23, 603950 г. Нижний Новгород, Российская Федерация, bullpit@rambler.ru. 